\title{
APRESENTAÇÃO
}

\section{TRADUÇÃO AUDIOVISUAL, ACESSIBILIDADE: UMA REVIRAVOLTA NA TRADUÇÃO (TERMO E CONCEITO)?}

\author{
Maria Paula Frota e Marcia A. P. Martins
}

Reunimos, neste décimo primeiro número da Tradução em Revista, a produção de docentes e pesquisadores que se dedicam ao campo da tradução audiovisual (TAV), quer como objeto de reflexão, quer como atividade profissional. $\mathrm{O}$ volume contempla a diversidade da área, que de um início restrito à legendagem e à dublagem para cinema e TV expandiu-se nas últimas décadas de modo a contemplar um grande número de modalidades, como demonstra o mapeamento feito por Eliana Franco e Vera Araújo no artigo inaugural, "Questões terminológico-conceituais no campo da tradução audiovisual (TAV)".

Esse trabalho - mais um da dupla de pesquisadoras brasileiras que vêm pioneiramente desbravando a área da TAV em nosso país — traz uma contribuição valiosa ao campo mais amplo dos estudos da tradução, na medida em que analisa as diferentes práticas, conceitos e termos que vêm se constituindo na esteira das novas mídias e assim conformando o complexo campo da tradução audiovisual. Sem perder o fôlego, as autoras discutem uma a uma as várias atividades, considerando as especificidades de cada qual, as fronteiras menos ou mais nítidas entre elas, e propõem, em nossa língua, um rico mapa terminológico-conceitual.

Valemo-nos aqui de duas citações por elas feitas, ambas traduções de texto do também reconhecido autor Jorge Díaz Cintas, acreditando que, somadas, essas citações expressam muito bem o interessante destino, digamos assim, que vem sendo dado à tradução como um todo por seus estudiosos. Esse destino ou percurso a que nos referimos compreende dois momentos que gostaríamos de destacar. O primeiro consiste — sobretudo graças ao recurso que se fez à tipologia proposta por Roman Jakobson em meados do século passado - na consolidação, como atividades tradutórias, das transformações interlinguais audiovisuais, as quais se dão a ver apenas na oralidade ou na combinação oralidade-escrita. O segundo momento, igualmente ou mais radical em seu abalo da noção jakobsoniana de "tradução propriamente dita" — ao trabalhar com 
transformações intersemióticas e intralinguais, a audiodescrição e a legenda para surdos e ensurdecidos -, pode ser entendido como fase inicial de uma reviravolta: a transformação da tradução, termo e conceito, em acessibilidade.

Com essa ideia em mente, leiamos as duas citações tão bem recortadas e traduzidas por Franco e Araújo:

\begin{abstract}
Na sua acepção primária, a TAV foi usada para encapsular práticas de tradução diferentes usadas na mídia audiovisual - cinema, televisão, VHS — nas quais há a transferência de uma língua-fonte para uma língua-meta. A dublagem e a legendagem são as mais populares na profissão e as mais conhecidas pelo público, mas há também outras tais como voice-over, dublagem parcial, narração e interpretação. A tradução para o espetáculo ao vivo foi adicionada a essa taxonomia num estágio posterior e foi assim que a supra-legendagem [surtitling] para a ópera e o teatro também foi incluída. A mudança de língua que acontece em todos esses casos foi um fator decisivo para nomear essas práticas como tradução. (Diaz Cintas 2005, apud Franco \& Araújo, neste volume, grifo nosso)

Eu gostaria de expandir o conceito e argumentar que, em essência, dublar, legendar ou traduzir em voice-over um programa é compartilhar com a ideia de acessibilidade da mesma forma que a LSE e a AD. Apenas os públicos-alvo é que são diferentes. Se $o$ desafio é uma barreira linguística ou sensorial, o objetivo do processo tradutório é exatamente o mesmo: facilitar o acesso a uma fonte de informação e entretenimento anteriormente hermética. Nesse sentido, a acessibilidade se torna um denominador comum que permeia essas práticas. (idem, ibidem, grifos nossos)
\end{abstract}

Já que estamos falando de autores pioneiros na área, talvez seja interessante antes de passarmos para a apresentação dos demais artigos aqui publicados e com vistas aos leitores menos familiarizados com a tradução audiovisual - abrirmos um parêntese para mencionar que o tema do presente número de Tradução em Revista já foi objeto de dois outros periódicos nacionais: a TradTerm de 2007 e a Cadernos de Tradução, que em 2005.2 teve um dossiê sobre a TAV e em 2001.1 tematizou a tradução intersemiótica. Ainda como indicações para os leigos ou novatos, merecem ser trazidas três publicações internacionais de grande valor: a coletânea de 2008 intitulada Between text and image, organizada por Delia Chiaro, Christine Heiss e Chiara Bucaria; o livro de Jorge Díaz Cintas e Aline Remael, Audiovisual Translation: Subtitling, publicado em 2007; e o número da revista The Translator de 2003, organizado por Yves Gambier.

Assim como o referido artigo inaugural de Franco e Araújo, outros cinco artigos aqui publicados constituem-se como mapeamentos, não da totalidade da área, como fizeram as duas autoras, mas de recortes da TAV. O estudo de Sabrina Martinez, intitulado "Tecnologia digital, acessibilidade e novos mercados para o tradutor audiovisual", consiste em um mapeamento (acreditamos poder caracterizá-lo assim) da 
tecnologia digital nas três últimas décadas, da nova legislação de acessibilidade e do impacto que ambos provocam no mercado da tradução audiovisual.

Dos outros quatro trabalhos-mapeamentos, consideramos que há uma analogia entre três deles na medida em que traçam um panorama, principalmente no Brasil, de três subáreas da TAV, respectivamente, a audiodescrição, o closed caption e o funsubbing:

Larissa Costa e Maria Paula Frota, visando a divulgação da audiodescrição (AD), exploraram o campo com a proposta de apresentar os seus primeiros passos àqueles leitores interessados em iniciar-se no tema - sua história, suas modalidades, seus profissionais. Enfatizam a relevância político-social da atividade, que se constitui como uma forma de acessibilidade e inclusão social. Daí por que reforçam a necessidade de ela ser mais conhecida, mais estudada e, principalmente, muito mais adotada pelas mídias e eventos audiovisuais e culturais como um todo.

Carolina Selvatici constrói um panorama do closed caption no Brasil, ao mesmo tempo em que desenvolve uma discussão teórica a respeito do conceito de tradução e a possibilidade de atribuir tal estatuto à modalidade apresentada.

Bianca Bold faz o mesmo, mas tendo como objeto a legendagem criada por fãs, tema que está começando a despertar o interesse acadêmico. Em "The Power of Fan Communities: An Overview of Fansubbing in Brazil", a autora aborda inicialmente o surgimento dos chamados "prosumidores" - consumidores que produzem conteúdo para seus pares - , bem como as motivações e a evolução do fansubbing, para então enfocar esse fenômeno no Brasil, não só examinando sua organização e práticas atuais mas também comparando e contrastando tais práticas com as da legendagem comercial brasileira.

O sexto e último trabalho desse primeiro conjunto é o de Vera Santiago Araújo, agora a quatro mãos com Ana Katarinna Pessoa do Nascimento, intitulado "Investigando parâmetros de legendas para surdos e ensurdecidos no Brasil". Também esse artigo faz o mapeamento de uma subárea da TAV, a de legendas para surdos e ensurdecidos, LSE, igualmente preocupado em apresentar o seu objeto no contexto nacional. Além desse panorama, as autoras apresentam uma pequena revisão dos estudos em LSE realizados na Universidade Estadual do Ceará e desenvolvem um estudo de caso, o qual consiste numa "pesquisa exploratória que investiga a recepção 
dos parâmetros da LSE propostos por um grupo de surdos de Fortaleza, que foram expostos a diferentes parâmetros de LSE por oito meses".

Esse trabalho de Araújo e Nascimento, por fazer um mapeamento e também um estudo de caso, representa uma interessante ponte entre os seis artigos já mencionados, todos eles "mapeamentos", e os que passamos a apresentar, todos eles estudos de caso, igualmente a partir de produtos culturais brasileiros e/ou veiculados no nosso mercado.

Iniciamos com o texto "Confronting Amateur and Academic Audiodescription: A Brazilian Case Study", também de Eliana Franco, neste caso em co-autoria com Sandra Farias, Íris Fortunato e Manoela da Silva. Elas analisam a satisfação de usuários relativamente à audiodescrição de filmes, a partir da reação de um grupo de deficientes visuais da cidade de Salvador a duas versões audiodescritas de um filme de DVD comercializado no Brasil, Irmãos de fé: uma versão preparada pelo diretor do DVD sem qualquer conhecimento prévio dessa modalidade, e outra, por um grupo de pesquisa acadêmica que tem estudado e praticado a audiodescrição de forma consistente. Os resultados indicam que a compreensão do conteúdo, entre outros fatores, é sem dúvida otimizada pela versão acadêmica.

Maíra Porto Ferreira investiga a tradução do humor nas legendas de duas versões em português do Brasil (para cinema e VHS) do filme Deconstructing Harry, produzido e dirigido por Woody Allen, distribuído no mercado brasileiro com o título Desconstruindo Harry. Tomando como base a teoria do humor de Victor Raskin (1985), complementada pelas ideias de Sigmund Freud (1905) e Henri Bergson (1900) sobre o tema, o trabalho analisa a construção linguística de algumas situações de humor e as estratégias adotadas para a sua tradução sob forma de legendas, buscando assim associar teoria e prática no campo dos Estudos da Tradução.

O texto de Elizabeth Ramos, "A Betty adormecida", faz uma impressionante descrição da animação Isabelle au bois dormant (do canadense Claude Cloutier), vendo nessa animação pós-moderna uma ressignificação intersemiótica de A bela adormecida. O que torna o trabalho de Ramos ainda mais interessante, e convergente com o tema da TAV, é considerá-lo um (pré-)roteiro de audiodescrição, o que pode ser favorecido pela ausência de fala. Por outro lado, devido à riqueza de imagens, em grande parte citações, essa audiodescrição talvez seja mais adequada a um público com deficiência visual adquirida. 
No estudo de caso "Da oralidade à legenda: reflexão em torno de um trabalho de legendagem", Adriana Carina Álvarez analisa a criação das legendas em português do Brasil do filme equatoriano Que tan lejos, o qual, além de se caracterizar por diálogos informais e contemporâneos, apresenta um interessante confronto entre duas variedades dialetais do castelhano. A autora também se detém sobre as dificuldades adicionais que esses fatores representam para o trabalho de tradução, voltado para a TV.

Em seguida, fechando a parte do volume que compreende cinco estudos de caso, temos a valiosa contribuição do professor, tradutor e pesquisador italiano Gian Luigi De Rosa, que vem se dedicando, entre outros temas da TAV, à tradução do humor. Diferentemente de Ferreira, que tratou do assunto apoiando-se na legendagem brasileira de um filme de Woody Allen, De Rosa examina a problemática tradução do humor ilustrando-a com um complexo caso de dublagem, para a "língua de Dante", de uma variante do português do Brasil, no contexto de um desenho animado. Em "Chico Bento no shopping", o autor analisa estratégias tradutórias empregadas na dublagem italiana paralelamente ao confronto de formas de humor verbal presentes no texto de partida e os resultados daquelas estratégias no texto de chegada.

O texto que fecha este número de Tradução em Revista consiste em uma tradução do artigo de P. A. Skantze - "Watching in Translation: Performance and the Reception of Surtitles" - que desenvolve uma discussão sobre as legendas eletrônicas, cada vez mais comuns no contexto operístico e também usadas em peças teatrais e mostras de cinema. Como diz a autora, o trabalho "explora a experiência fenomenológica de 'assistir com tradução', enfocando especialmente a recepção de uma tradução projetada, o papel do espectador como participante ativo no processo de tradução durante o espetáculo e a intervenção relativamente recente de algumas companhias teatrais no sentido de tornar o processo tradutório parte da encenação".

Esperamos que este volume voltado para a tradução audiovisual contribua para aprofundar o conhecimento sobre um campo em contínua expansão e com o importante papel social de promover a tradução como acessibilidade - e, como procuramos indicar no título, com prováveis desdobramentos, mais profundos, na área da tradução tal como hegemônica e tradicionalmente compreendida. 